\title{
Demand analysis of meat in Malaysia
}

\begin{abstract}
One distinct change in Malaysians' food consumption behavior has been the preference toward meat products. Thus it is meaningful to gain insight of meat consumption patterns. As the market becomes increasingly market-led, information on current meat consumption patterns is required to assess how they are likely to change as prices and incomes change. This study attempts to provide a better understanding of demand for meat products in Malaysia. By utilizing data from Household Expenditure Survey 2004/2005, Engel curve analysis was conducted to derive income elasticities of meat products from QUAIDS model. The estimated income elasticities show that current food consumption patterns are showing signs of convergence toward a Western diet, exhibiting tendency for preference toward red meats (mutton and beef) over white meats (poultry and pork). The estimated elastic ownprice elasticities indicate that Malaysian consumers are sensitive to the change in prices of the meat products, with other things remain constant.
\end{abstract}

Keyword: Meat; Consumption patterns; Quadratic almost ideal demand system model; Engel function; Income elasticity; Own-price elasticity 